University of Nebraska - Lincoln

DigitalCommons@University of Nebraska - Lincoln

\title{
High-Pressure Micellar Solutions of Polystyrene-block- polybutadiene and Polystyrene-block-polyisoprene in Propane Exhibit Cloud-Pressure Reduction and Distinct Micellization End Points
}

Winoto Winoto

Soft Materials Laboratory, Department of Chemical \& Petroleum Engineering, UniVersity of Wyoming, Laramie, Wyoming

Sugata P. Tan

Soft Materials Laboratory, Department of Chemical \& Petroleum Engineering, UniVersity of Wyoming, Laramie, Wyoming

Youqing Shen

Soft Materials Laboratory, Department of Chemical \& Petroleum Engineering, UniVersity of Wyoming, Laramie, Wyoming

Maciej Radosz

Soft Materials Laboratory, Department of Chemical \& Petroleum Engineering, UniVersity of Wyoming, Laramie, Wyoming

Kollhw'thisiongd additional works at: https://digitalcommons.unl.edu/usdoepub

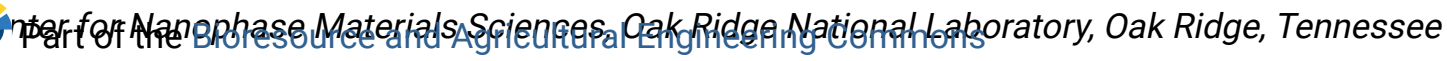

See nexi page for additional authors

Winoto, Winoto; Tan, Sugata P.; Shen, Youqing; Radosz, Maciej; Hong, Kunlun; and Mays, Jimmy W., "HighPressure Micellar Solutions of Polystyrene-block-polybutadiene and Polystyrene-block-polyisoprene in Propane Exhibit Cloud-Pressure Reduction and Distinct Micellization End Points" (2009). US Department of Energy Publications. 70.

https://digitalcommons.unl.edu/usdoepub/70

This Article is brought to you for free and open access by the U.S. Department of Energy at DigitalCommons@University of Nebraska - Lincoln. It has been accepted for inclusion in US Department of Energy Publications by an authorized administrator of DigitalCommons@University of Nebraska - Lincoln. 


\section{Authors}

Winoto Winoto, Sugata P. Tan, Youqing Shen, Maciej Radosz, Kunlun Hong, and Jimmy W. Mays 


\title{
High-Pressure Micellar Solutions of Polystyrene-block-polybutadiene and Polystyrene-block-polyisoprene in Propane Exhibit Cloud-Pressure Reduction and Distinct Micellization End Points
}

\author{
Winoto Winoto, Sugata P. Tan, Youqing Shen, and Maciej Radosz* \\ Soft Materials Laboratory, Department of Chemical \& Petroleum Engineering, University of Wyoming, \\ Laramie, Wyoming 82071-3295
}

Kunlun Hong and Jimmy W. Mays

Center for Nanophase Materials Sciences, Oak Ridge National Laboratory, Oak Ridge, Tennessee 37831-6494

Received February 5, 2009; Revised Manuscript Received April 3, 2009

\begin{abstract}
Micellar solutions of polystyrene-block-polybutadiene and polystyrene-block-polyisoprene in propane are found to exhibit significantly lower cloud pressures than the corresponding hypothetical nonmicellar solutions. Such a cloud-pressure reduction indicates the extent to which micelle formation enhances the apparent diblock solubility in near-critical and hence compressible propane. Concentration-dependent pressure-temperature points beyond which no micelles can be formed, referred to as the micellization end points, are found to depend on the block type, size, and ratio. The cloud-pressure reduction and the micellization end point measured for styrene-diene diblocks in propane should be characteristic of all amphiphilic diblock copolymer solutions that form micelles in compressible solvents.
\end{abstract}

\section{Introduction}

Block copolymer molecules consist of two or more blocks of segments with distinctly different affinities to a solvent. If the solvent is selective enough, such molecules can form spherical micelles, ${ }^{1}$ which consist of a solvent-phobic core and solvent-philic corona. This capacity to self-assemble into micelles has led to extensive research on and numerous practical applications of block copolymers, ${ }^{2,3}$ primarily in relatively incompressible liquid solvents, ${ }^{4}$ but there are a few references to compressible micellar solutions in carbon dioxide ${ }^{5-10}$ as well.

In our recent work, we focused on model styrene-diene block copolymers in a compressible alkane solvent, such as propane, to understand their bulk and micellar phase behavior. For example, polystyrene-block-polyisoprene was demonstrated to form micelles in supercritical and subcritical propane that exhibit micellization and micelle decomposition transitions induced by changing either pressure or temperature or both. ${ }^{11}$ In other words, such systems exhibit critical micelle temperatures, which are a function of pressure, and vice versa. At the onset of micellization, a trace of free polystyrene was shown to cause a characteristic scattering peak, not only upon cooling-heating but also upon compression-decompression. At a constant polymer concentration, both micellization temperature and pressures were found to fall around a decreasing micellar phase boundary curve in pressure-temperature coordinates, which lies above the copolymer cloud-point curve and below the polystyrene cloud-point curve. The onset of micellization and the onset of bulk transition (cloud point) were not only measured but also realistically estimated ${ }^{12}$ for styrene-isoprene and styrenebutadiene block copolymers in propane from statistical associating fluid theory (SAFT1) using universal SAFT1 parameters characteristic of the segment volumes and segment energies. That study ${ }^{12}$ also provided a clue that the experimental cloud pressures of the micellar solutions were lower than those calculated from SAFT1 for a hypothetical random solution, but it did not explain and quantify the extent of such a cloud-

* Corresponding author. E-mail radosz@uwyo.edu. pressure reduction and its high-temperature limit. The latter is important because it represents a true, pressure-specific but pressure-independent equivalent of the "critical micelle temperature", referred to as the micellization end point (MEP).

Therefore, the goal of this work is to measure and calculate micellar and bulk (cloud) transitions in compressible solutions of polystyrene-block-polybutadiene and polystyrene-block-polyisoprene in propane to probe the extent to which micelle formation enhances the apparent diblock solubility, to quantify the pressure-temperature MEP beyond which no micelles can be formed and to characterize its dependence on the block type, size, and ratio.

\section{Experimental Section}

Materials. The homopolymers and diblock copolymers used in this work are either purchased or synthesized via living anionic polymerization using well-established vacuum line techniques, as documented in recent reviews. ${ }^{13,14}$ Briefly, the diblocks are prepared by sequential monomer addition, with sampling of the first block (polystyrene). Microstructure of the polybutadiene and polyisoprene is controlled through the choice of solvent and use of polar additions, tertiary amines, and ethers. ${ }^{15,16}$ Molecular weights and polydispersity indices are characterized using size exclusion chromatography (SEC) with online light scattering detection. Microstructure of the polydienes and composition of the block copolymers are determined using proton nuclear magnetic resonance ( ${ }^{1} \mathrm{H}$ NMR).

The polybutadiene and polyisoprene samples are at least $90 \%$ of the 1,4-addition type for both homopolymer and diblock copolymer. The molecular weights and polydispersity indices of all samples are provided in Table 1, including their short names.

The propane is $99.0 \%$ grade from Matheson Trigas, Inc., and used without further purification.

Terminology and Experimental Method. The onset of bulk phase transition of a clear polymer solution is usually observed as the onset of its turbidity and hence referred to as the "cloud point", that is, the pressure and temperature at which the homogeneous solution turns cloudy, referred to as the cloud pressure (CP) and the cloud temperature (CT). When the bulk phase transition occurs from a micellar solution, as opposed to a molecularly homogeneous 
Table 1. Polymers Used in This Work

\begin{tabular}{llll}
\hline \multicolumn{1}{c}{ polymer } & \multicolumn{1}{c}{ abbreviation } & \multicolumn{1}{c}{$M_{\mathrm{n}}{ }^{a}$} & $\mathrm{PDI}^{b}$ \\
\hline polystyrene & $\mathrm{S}(5)^{c}$ & 5.5 & 1.02 \\
polybutadiene & $\mathrm{B}(5)^{c}$ & 5.3 & 1.04 \\
polystyrene-block-polybutadiene & $\mathrm{S}-\mathrm{B}(5-5)^{c}$ & $5.4-5.35$ & 1.03 \\
& $\mathrm{~S}-\mathrm{B}(15-13)^{c}$ & $15.0-13.0$ & 1.05 \\
& $\mathrm{~S}-\mathrm{B}(16-9)$ & $15.5-9.4$ & 1.02 \\
& $\mathrm{~S}-\mathrm{B}(37-36)$ & $36.8-35.9$ & 1.01 \\
polystyrene-block-polyisoprene & $\mathrm{S}-\mathrm{I}(9-23)$ & $9.0-23.0$ & 1.01 \\
& $\mathrm{~S}-\mathrm{I}(11-10)^{c}$ & $11.5-10.5$ & 1.04
\end{tabular}

${ }^{a} M_{\mathrm{n}}=$ number-average molecular weight $(\mathrm{kg} / \mathrm{mol}) .{ }^{b}$ Polydispersity index $=M_{\mathrm{w}} / M_{\mathrm{n}} ; M_{\mathrm{w}}=$ weight-average molecular weight. ${ }^{c}$ Purchased from Polymer Source, Inc.

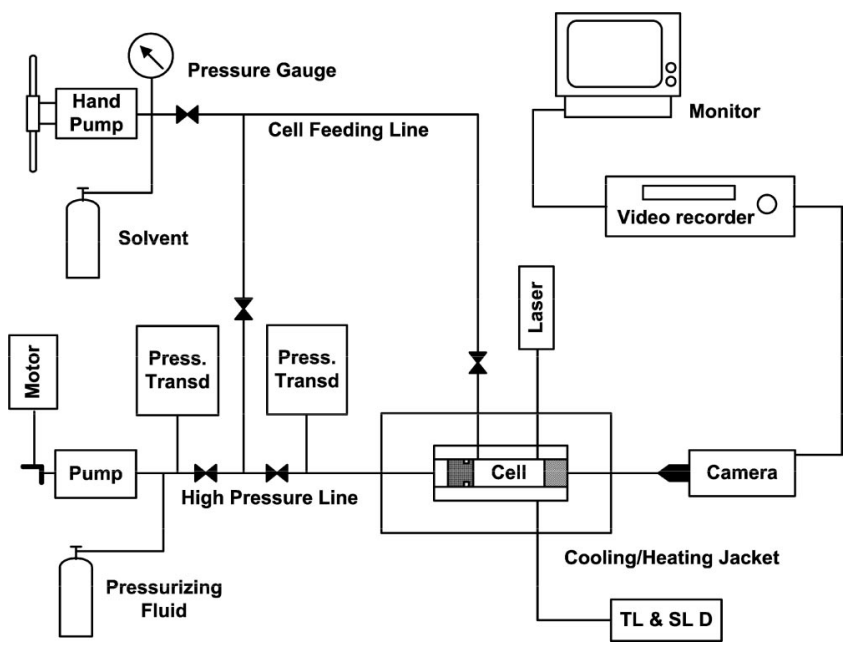

Figure 1. A simplified schematic of the apparatus. ${ }^{11}$

solution, such a transition is referred to as the micellar cloud point with its corresponding measured conditions, the micellar cloud pressure (MCP) and the micellar cloud temperature (MCT).

The micelle formation or decomposition in a block copolymer solution is measured from the change of the scattered-light intensity upon changing pressure at constant temperature, which results in the micellization pressure (MP), or changing temperature at constant pressure, which results in the micellization temperature (MT). The micelle-containing solution is referred to as the micellar solution, in contrast to the molecular solution observed upon micelle decomposition.

In this work, $\mathrm{CP}, \mathrm{MCP}$, and MP are measured in a small highpressure variable-volume cell coupled with transmitted- and scattered-light intensity probes and equipped with a borescope for visual observation of the phase transitions and with pressure and temperature probes accurate to within \pm 2 bar and $\pm 0.1{ }^{\circ} \mathrm{C}$, respectively.

In a typical experiment, a known amount of polymer $(0.5 \mathrm{wt} \%)$ and solvent is loaded into the cell, which is then brought to and maintained at a desired pressure and temperature, high enough for the polymer to form a molecular solution. A simplified schematic of the experimental setup is shown in Figure 1. A detailed description of the apparatus and experimental procedure can be found in Winoto et al. ${ }^{11}$ In this work, attempts to reproduce $\mathrm{CP}$, $\mathrm{MCP}$, and MP for different cell loads suggest that the measured data are reproducible to within 30 bar.

Computational Method. A version of statistical associating fluid theory referred to as SAFT $1{ }^{17}$ was demonstrated to represent the cloud points of molecular solutions of homopolymers and diblock copolymers in propane. ${ }^{12}$ SAFT1 parameters used in this work are the same as those previously derived from experimental CP data for propane solutions of polystyrene, ${ }^{18}$ polydienes, and their diblock copolymers. ${ }^{12}$ A sample result shown in Figure 2, redrawn from the data previously published by Tan et al., ${ }^{12}$ illustrates that SAFT1 can quantitatively estimate the $\mathrm{CP}$ for a $\mathrm{S}-\mathrm{B}(5-5)$ diblock and the corresponding homopolymers, all at a constant polymer concentration of $0.5 \mathrm{wt} \%$ in propane. This diblock is too small to

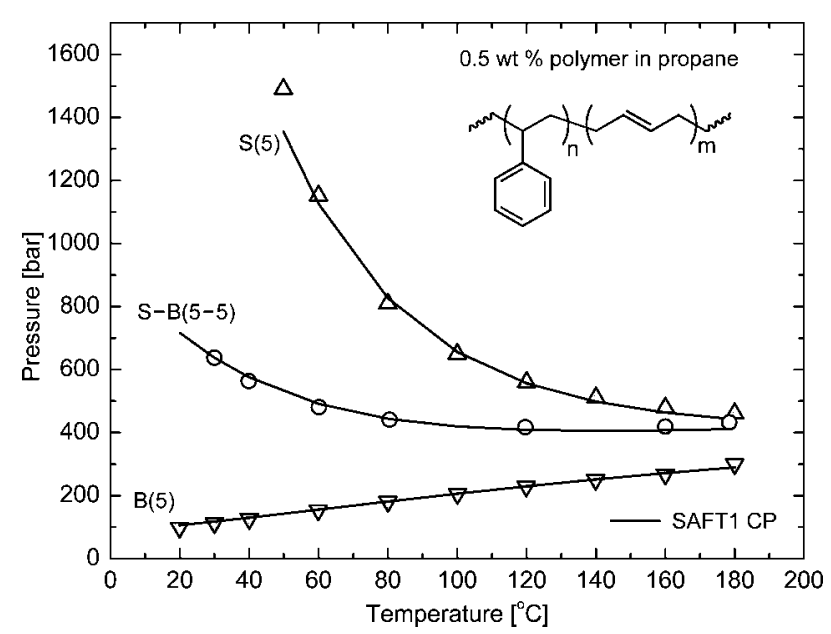

Figure 2. Cloud pressure (CP) as a function of temperature for $0.5 \mathrm{wt}$ $\%$ solutions of polystyrene (S) in propane, polybutadiene (B) in propane, and polystyrene-block-polybutadiene $(\mathrm{S}-\mathrm{B})$ in propane; SAFT1 represents $\mathrm{CP}$ of homopolymers and diblock copolymer. ${ }^{12}$

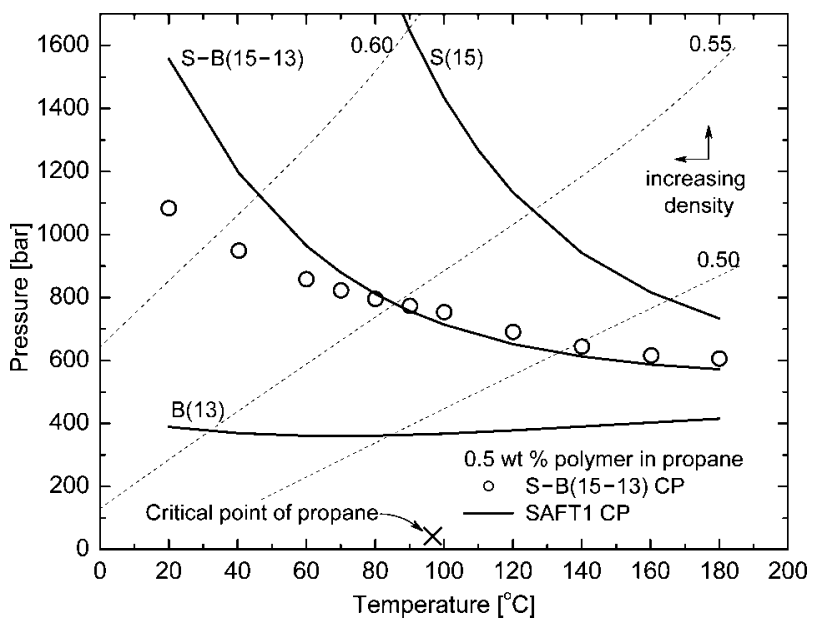

Figure 3. Cloud pressure as a function of temperature for $0.5 \mathrm{wt} \%$ polystyrene-block-polybutadiene $(\mathrm{S}-\mathrm{B})$ solution in propane and cloud pressure of the corresponding homopolymers, polystyrene (S) and polybutadiene (B), in the same solvent; the dotted curves stand for constant propane density ${ }^{19}$ in $\mathrm{g} / \mathrm{mL}$.

form micelles at the concentration and in the temperature range investigated in this work, but it illustrates that the CP data calculated for molecular solutions are in agreement with the experimental data and that the $\mathrm{CP}$ for a symmetric diblock falls roughly between the $\mathrm{CP}$ of the corresponding homopolymers of the same size as the blocks.

\section{Results and Discussion}

Building on this finding, we calculate CP data alone (assuming no micelle formation) for a larger diblock, $\mathrm{S}-\mathrm{B}(15-13)$ in propane, for which we have experimental data, and for its corresponding homopolymers, S(15) and B(13), for which we do not have experimental data. The results are shown in Figure 3 , including constant propane density curves (dotted). The CP calculated for the diblock (solid curve) is consistent with the measured CP (open circles) at temperatures higher than about $100{ }^{\circ} \mathrm{C}$, but it becomes progressively higher than the measured $\mathrm{CP}$ upon decreasing temperature, by as much as 500 bar at 20 ${ }^{\circ} \mathrm{C}$. This brings out a distinct change in slope of the measured $\mathrm{CP}$ around $100{ }^{\circ} \mathrm{C}$.

As it turns out, this change in cloud-point curve slope is caused by micellization observed for the $\mathrm{S}-\mathrm{B}(15-13)$ diblock copolymer in propane up to about $100{ }^{\circ} \mathrm{C}$, as illustrated in Figure 


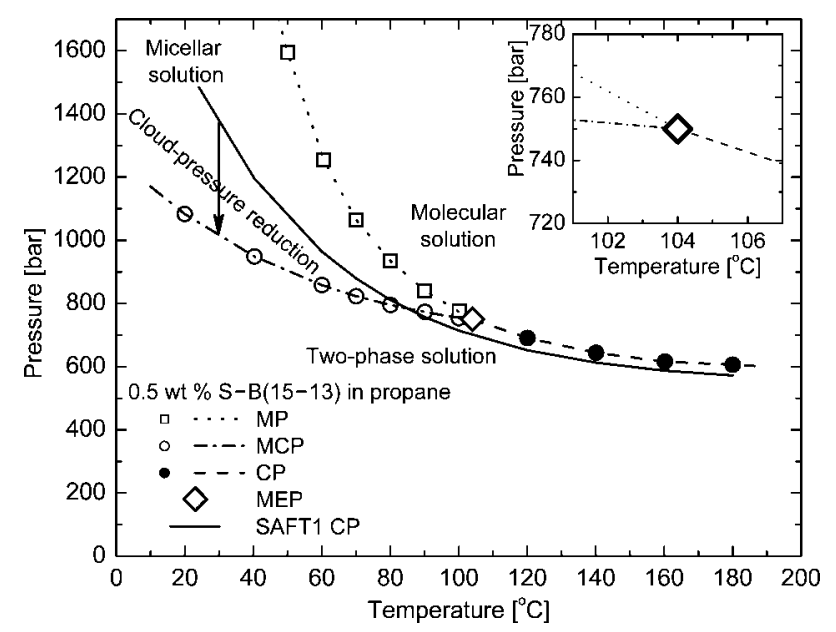

Figure 4. Cloud pressure (CP), micellar cloud pressure (MCP), and micellization pressure (MP) as a function of temperature for $0.5 \mathrm{wt} \%$ solution of polystyrene-block-polybutadiene $(\mathrm{S}-\mathrm{B}(15-13))$ in propane; cloud-point curve (dashed), micellar cloud-point curve (dash-dotted), and micellization boundary (dotted) intersect around a micellization end point (MEP), indicating the highest temperature at which micellization can occur for a constant-concentration solution, around 104 ${ }^{\circ} \mathrm{C}$ for a 0.5 wt $\% \mathrm{~S}-\mathrm{B}(15-13)$ in propane.

4 and amplified in the inset. The square points in Figure 4 indicate the measured micellization pressures (MP), the filled circles indicate the regular (molecular solution) cloud pressures (CP), and the open circles indicate the micellar cloud pressures (MCP). Hence, the micellar region in pressure-temperature coordinates is a wedge between the MCP curve, which indicates the onset of micelle aggregation and bulk precipitation upon cooling or decompressing the micellar solution, and the MP curve, which is the onset of micelle formation upon cooling or decompressing a disordered molecular solution. Since the propane density increases upon cooling and decreases upon decompression, as shown in Figure 3, there is no monotonic cause-and-effect relationship between the solvent density and micellization for this type of MP behavior (decreasing MP curve in pressure-temperature coordinates). That is, sometimes (e.g., upon isobaric cooling) increasing density induces micelle formation, but sometimes (e.g., upon isothermal compression) it induces micelle decomposition. Let us note that, for some other systems, with an increasing MP curve, such as that described in refs 5 and 6 , increasing density of the micellar solution upon cooling and compression always leads to micelle decomposition.

The solid curve in Figure 4 is the same calculated cloudpressure curve as in Figure 3 for a hypothetical molecular solution. The shift from the hypothetical molecular CP (solid curve) to the experimental MCP (dashed-dotted curve) will be referred to as the cloud-pressure reduction, illustrated with an arrow in Figure 4.

Such a cloud-pressure reduction means that the micelle formation enhances the diblock apparent solubility in propane; it takes lower pressure and hence density to make the diblock and propane completely miscible than it would have taken for a corresponding molecular solution, in the absence of micelles. This is because the butadiene corona, which has more favorable interactions with propane than the styrene core, shields the styrene core from propane, which inhibits a bulk phase separation and hence reduces its onset pressure (MCP relative to $\mathrm{CP}$ ).

The highest temperature at which the micellization can be observed, the temperature-pressure tip of the micellar region wedge, shown with a diamond in Figure 4, is referred to as the micellization end point (MEP). MEP corresponds to the socalled critical micelle temperature (MT in this work), which is

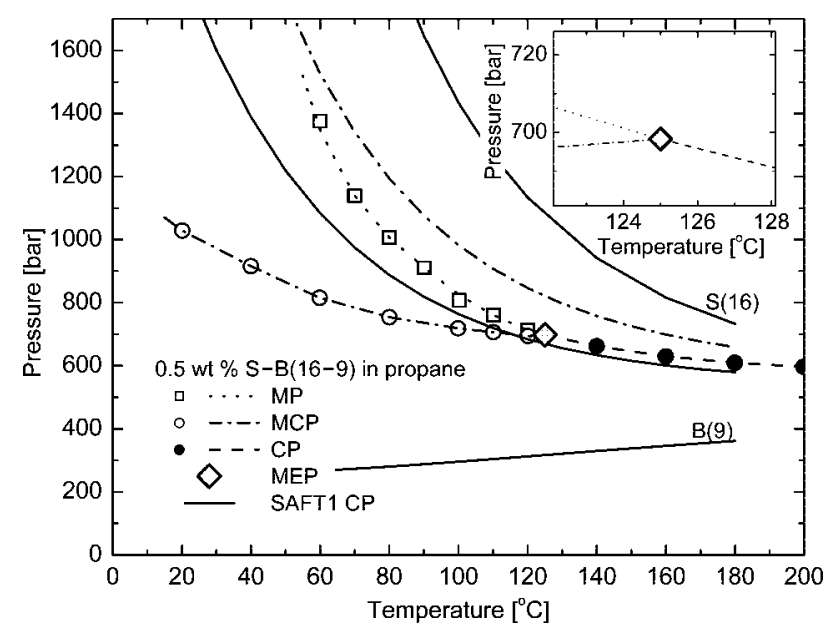

Figure 5. Micellization pressure (MP), micellar cloud pressure (MCP), cloud pressure (CP), and micellization end point (MEP around 125 ${ }^{\circ} \mathrm{C}$ ) for $0.5 \mathrm{wt} \%$ solution of polystyrene-block-polybutadiene $(\mathrm{S}-\mathrm{B}(16-9))$ in propane and calculated cloud pressures for the corresponding homopolymers in the same solvent.

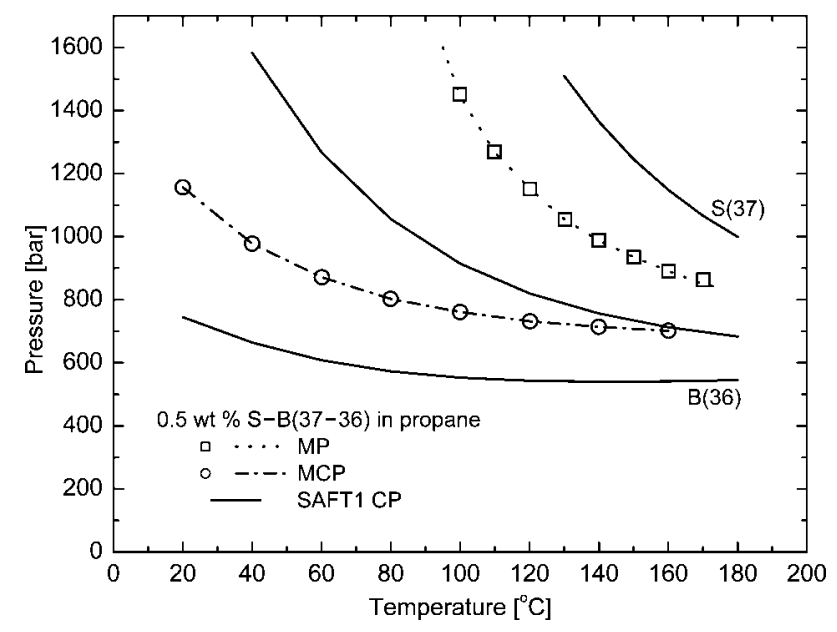

Figure 6. Micellization pressure (MP) and micellar cloud pressure (MCP) indicate micellization end point (MEP) above $200{ }^{\circ} \mathrm{C}$ for 0.5 wt $\%$ solution of polystyrene-block-polybutadiene $(\mathrm{S}-\mathrm{B}(37-36))$ in propane and calculated cloud pressures of the corresponding homopolymers in the same solvent.

a function of pressure and concentration. By contrast, MEP has a characteristic pressure, but it is pressure independent for a given concentration.

For a given solvent, the MEP temperature should depend on the block type, size, and ratio. In order to test and illustrate this hypothesis, we characterize the molecular and micellar propane solutions of additional model styrene-diene diblocks: $\mathrm{S}-\mathrm{B}$ (16-9), $S-B(37-36), S-I(9-23)$, and $S-I(11-10)$. The results are shown in Figures 5-8. A summary of MEP temperatures and their characteristic pressures is given in Table 2.

Figures 4-8 illustrate that the MEP pressure and especially temperature vary for a given block type as a function of the block size and ratio. For example, Figure 5 illustrates that increasing the styrene/diene block ratio, at about the same styrene size, compared to that shown in Figure 4, increases the MEP temperature.

Figure 6 shows that a relatively large styrene block in $\mathrm{S}-\mathrm{B}(37-36)$ shifts the MEP temperature slightly beyond the experimental range, above $200{ }^{\circ} \mathrm{C}$; if needed, it can be safely estimated through extrapolation. A previous example of $\mathrm{S}-\mathrm{B}(5-5)$ in propane shown in Figure 2 illustrates a case where the true MEP temperature lies well below the experimental 


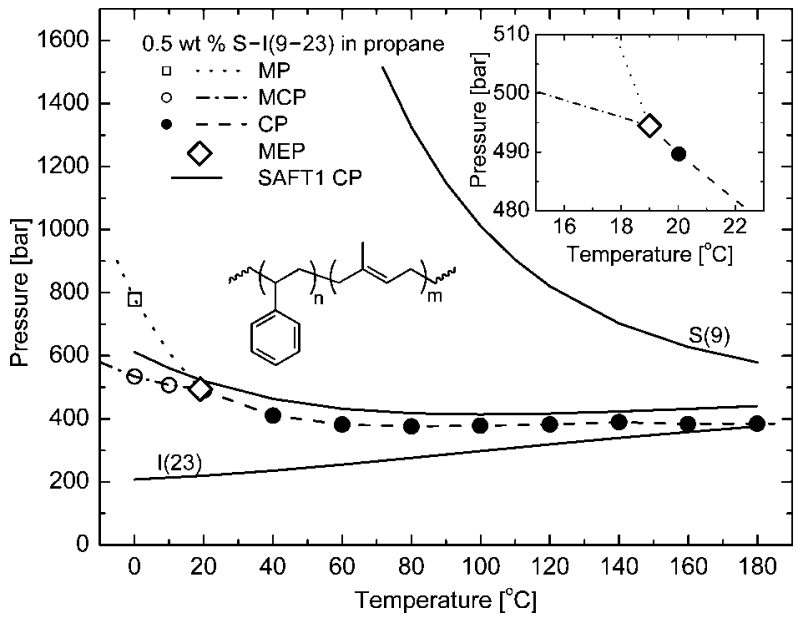

Figure 7. Micellization pressure (MP), micellar cloud pressure (MCP), cloud pressure $(\mathrm{CP})$, and micellization end point (MEP around $19{ }^{\circ} \mathrm{C}$ ) for $0.5 \mathrm{wt} \%$ solution of polystyrene-block-polyisoprene $(\mathrm{S}-\mathrm{I}(9-23))$ in propane (new $\mathrm{CP}$ data consistent with those from ref 12 which did not include the MCP, MP, and MEP) and calculated cloud pressures of the corresponding homopolymers in the same solvent.

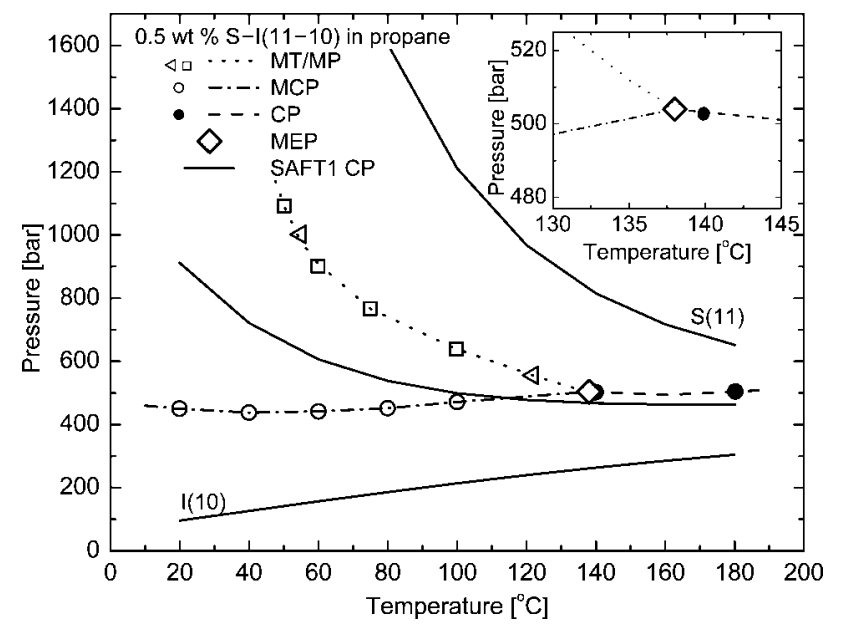

Figure 8. Micellization temperature (MT), micellization pressure (MP), micellar cloud pressure (MCP), cloud pressure (CP), and micellization end point (MEP around $138{ }^{\circ} \mathrm{C}$ ) for $0.5 \mathrm{wt} \%$ solution of polystyreneblock-polyisoprene $(\mathrm{S}-\mathrm{I}(11-10))$ in propane (replotted on the basis of the experimental data from ref 12 which did not include MEP) and calculated cloud pressures for the corresponding homopolymers in the same solvent.

\section{Table 2. Micellization End Point}

\begin{tabular}{cc}
\hline 0.5 wt \% copolymer in propane & micellization end point (MEP) \\
\hline $\mathrm{S}-\mathrm{B}(5-5)$ & $<0^{\circ} \mathrm{C}$ \\
$\mathrm{S}-\mathrm{B}(15-13)$ & $104^{\circ} \mathrm{C} ; 750 \mathrm{bar}$ \\
$\mathrm{S}-\mathrm{B}(16-9)$ & $125^{\circ} \mathrm{C} ; 698 \mathrm{bar}$ \\
$\mathrm{S}-\mathrm{B}(37-36)$ & $>200^{\circ} \mathrm{C}$ \\
$\mathrm{S}-\mathrm{I}(9-23)$ & $19^{\circ} \mathrm{C} ; 495 \mathrm{bar}$ \\
$\mathrm{S}-\mathrm{I}(11-10)$ & $138^{\circ} \mathrm{C} ; 504 \mathrm{bar}$
\end{tabular}

temperature range. Instead of extending the temperature range to lower temperatures for small polymers or to higher temperatures for large polymers, an alternative approach to prove micellization is to increase the concentration of the small polymer (which increases its MEP temperature) or to decrease the concentration of the large polymer (which decreases its MEP temperature).

Figures 7 and 8 also suggest that increasing the isoprene block size (molecular weight) reduces the MEP temperature. More systematic work is needed to understand the effects of the block type (butadiene vs isoprene), size, ratio, and crystallizability and of the polymer concentration, not only on MEP but also on CP, MCP, and MP for symmetric diblocks and asymmetric diblocks. Such data, explored, analyzed, and documented in detail in a separate project, are needed to exploit compressible solvents for solubilizing block copolymers and other solutes.

\section{Conclusion}

Micellar solutions of polystyrene-block-polybutadiene and polystyrene-block-polyisoprene in propane are found to exhibit significantly lower cloud pressures than the corresponding hypothetical nonmicellar solutions, which is a measure of the polymer solubility enhancement due to micelle formation. Such a solubility enhancement is produced by the solvent-philic micelle corona that shields its core from the solvent. Concentration-dependent pressure-temperature points beyond which no micelles can be formed, referred to as the micellization end points, depend on the block type, size, and ratio. The cloudpressure reduction and the micellization end point measured for styrene-diene diblocks in propane should be characteristic of all amphiphilic diblock copolymer solutions that form micelles in compressible solvents.

Acknowledgment. This work is funded by a National Science Foundation Grant CTS-0625338 at the University of Wyoming. Part of this research was done at Oak Ridge National Laboratory's Center for Nanophase Materials Sciences, which was sponsored by the Scientific User Facilities Division, Office of Basic Energy Sciences, U.S. Department of Energy, through User Project CNMS2006-114.

\section{References and Notes}

(1) Quintana, J. R.; Villacampa, M.; Katime, I. A. Macromolecules 1993, 26, 601-605.

(2) Hamley, I. W. The Physics of Block Copolymers; Oxford University Press: New York, 1998.

(3) Legge, N. R.; Holden, G.; Schroeder, H. E. Thermoplastic Elastomers; Hanser Publishers: Munich, 1987.

(4) Loh, W. In Encyclopedia of Surface and Colloid Science; Hubbard, A., Ed.; Marcel Dekker: New York, 2002; p 802.

(5) Buhler, E.; Dobrynin, A. V.; DeSimone, J. M.; Rubinstein, M. Macromolecules 1998, 31, 7347-7355.

(6) Zhou, S.; Chu, B. Macromolecules 1998, 31, 7746-7755.

(7) Triolo, F.; Triolo, A.; Triolo, R.; Londono, J. D.; Wignall, G. D.; McClain, J. B.; Betts, D. E.; Wells, S.; Samulski, E. T.; DeSimone, J. M. Langmuir 2000, 16, 416-421.

(8) Triolo, R.; Triolo, A.; Triolo, F.; Steytler, D. C.; Lewis, C. A.; Heenan, R. K.; Wignall, G. D.; DeSimone, J. M. Phys. Rev. E 2000, 61, 46404643.

(9) Triolo, A.; Triolo, F.; Celso, F. L.; Betts, D. E.; McClain, J. B.; DeSimone, J. M.; Wignall, G. D.; Triolo, R. Phys. Rev. E 2000, 62, 5839-5842.

(10) Colina, C. M.; Hall, C. K.; Gubbins, K. E. Fluid Phase Equilib. 2002, 194-197, 553-565.

(11) Winoto, W.; Adidharma, H.; Shen, Y.; Radosz, M. Macromolecules 2006, 39, 8140-8144.

(12) Tan, S. P.; Winoto, W.; Radosz, M. J. Phys. Chem. C 2007, 111, 15752-15758.

(13) Hadjichristidis, N.; Pitsikalis, M.; Pispas, S.; Iatrou, H. Chem. Rev. 2001, 101, 3747-3792.

(14) Uhrig, D.; Mays, J. W. J. Polym. Sci., Part A: Polym. Chem. 2005, 43, 6179-6222.

(15) Hattam, P.; Gauntlett, S.; Mays, J. W.; Hadjichristidis, N.; Young, R. N.; Fetters, L. J. Macromolecules 1991, 24, 6199-6209.

(16) Mays, J. W.; Hadjichristidis, N.; Fetters, L. J. Macromolecules 1984, $17,2723-2728$.

(17) Adidharma, H.; Radosz, M. Ind. Eng. Chem. Res. 1998, 37, 44534462.

(18) Tan, S. P.; Meng, D.; Plancher, H.; Adidharma, H.; Radosz, M. Fluid Phase Equilib. 2004, 226, 189-194.

(19) The density data for pure propane are obtained from National Institute of Standards and Technology Chemistry WebBook found at http:// webbook.nist.gov/chemistry/fluid/. These data are fitted to an exponential decay equation as a function of pressure to approximate propane density at higher pressure through extrapolation. 